\title{
Concordance of metabolic enzyme genotypes assayed from paraffin-embedded, formalin-fixed breast tumors and normal lymphatic tissue
}

This article was published in the following Dove Press journal:

Clinical Epidemiology

21 October 2010

Number of times this article has been viewed

\author{
Thomas P Ahern' \\ Mariann Christensen ${ }^{2}$ \\ Deirdre P Cronin-Fenton ${ }^{3}$ \\ Kathryn L Lunetta ${ }^{4}$ \\ Carol L Rosenberg ${ }^{5}$ \\ Henrik Toft Sørensen ${ }^{3}$ \\ Timothy L Lash ${ }^{3}$ \\ Stephen Hamilton-Dutoit ${ }^{2}$ \\ 'Department of Epidemiology, \\ Boston University School of Public \\ Health, Boston, Massachusetts; \\ ${ }^{2}$ Institute of Pathology; ${ }^{3}$ Department \\ of Clinical Epidemiology, Aarhus \\ University Hospital, Aarhus, Denmark; \\ ${ }^{4}$ Department of Biostatistics, Boston \\ University School of Public Health, \\ Boston, Massachusetts; ${ }^{5}$ Hematology/ \\ Oncology Section, Department of \\ Medicine, Boston University School of \\ Medicine, Boston, Massachusetts, USA
}

Correspondence: Thomas P Ahern

7I5 Albany Street T3E, Boston,

MA 02118, USA

Tel + I 6I7-638-7775

$\mathrm{Fax}+\mid$ 617-638-4448

Email tpa@bu.edu
Objectives: Translational epidemiology studies often use archived tumor specimens to evaluate genetic hypotheses involving cancer outcomes. When the exposure of interest is a germline polymorphism, a key concern is whether the genotype assayed from tumor-derived DNA is representative of the germline. We evaluated the concordance between breast tumor-derived and normal lymph node-derived genotypes for three polymorphic tamoxifen-metabolizing enzymes.

Methods: We assayed paired DNA samples extracted from archived tumor and normal lymph node tissues from 106 breast cancer patients. We used TaqMan assays to determine the genotypes of three enzyme variants hypothesized to modify tamoxifen effectiveness, ie, CYP2D $6^{*} 4$, $U G T 2 B 15^{*} 2$, and $U G T 1 A 8^{*} 2$. We assessed genotype agreement between the two DNA sources by calculating the percent agreement and the weighted kappa statistic.

Results: We successfully obtained genotypes for CYP2D $6^{*} 4, U G T 2 B 15^{*} 2$, and UGT1A $8^{*} 2$ in $99 \%, 100 \%$, and $84 \%$ of the paired samples, respectively. Genotype concordance was perfect for the CYP2D6*4 and UGT1A8*2 variants (weighted kappa for both $=1.00 ; 95 \%$ confidence interval $[\mathrm{CI}] 1.00,1.00$ ). For $U G T 2 B 15^{*} 2$, one pair out of 106 gave a discordant result that persisted over several assay repeats.

Conclusions: We observed strong agreement between DNA from breast tumors and normal lymphatic tissue in the genotyping of polymorphisms in three tamoxifen-metabolizing enzymes. Genotyping DNA extracted from tumor tissue avoids the time-consuming practice of microdissecting adjacent normal tissue when other normal tissue sources are not available. Therefore, the demonstrated reliability of tumor-derived DNA allows resources to be spent instead on increasing sample size or the number of polymorphisms examined.

Keywords: molecular epidemiology, breast neoplasms, cytochrome P450 CYP2D6, glucuronosyltransferase

\section{Introduction}

Translational clinical epidemiology studies frequently use tissue archives as a resource for bioassays of cellular and molecular features, such as germline genotype or protein expression in a tumor. The utility of archived tissues is tempered by inherent weaknesses of stored biologic material, for example, degradation of macromolecules over time, or the questionable representativeness of a tissue sample to a whole tumor or to a person. ${ }^{1-4}$ A specific example of the latter limitation is the use of archived breast tumors to assay germline genotypes of drug-metabolizing enzymes, which may modify the effectiveness of adjuvant therapies in terms of disease recurrence and survival. ${ }^{5}$ In such studies, it is uncommon to have available samples from more reliable sources of germline DNA, such as buccal cells or peripheral blood, and it is 
therefore necessary to assume that a tumor-derived genotype is representative of a patient's germline. ${ }^{6,7}$ However, there is cause for skepticism over this assumption, owing to a variety of potential DNA alterations in tumors that may interfere with accurate genotyping. ${ }^{2,3,8-10}$

Earlier studies have explored genotype concordance between reliable sources of germline DNA and breast tumor or tumor-adjacent tissue. Schneider et al compared genotype agreement for a panel of angiogenesis gene polymorphisms in 17 breast tumor samples with paired lymph node samples. ${ }^{11}$ Xie et al compared genotype agreement for five genes at loci with high rates of loss of heterozygosity in paired DNA samples from peripheral blood and microdissected breast tumor-adjacent normal tissue in 106 subjects. ${ }^{12}$ While both of these studies demonstrated $100 \%$ concordance between the different DNA sources, the use of tumor-adjacent normal tissue by Xie et al and the small sample size enrolled by Schneider et al leave open the question of whether DNA derived from formalin-fixed, paraffin-embedded (FFPE) breast tumor sections provides a reliable medium for the assay of germline genotype. Here we report the results from a large study of the concordance between genotypes of three tamoxifen-metabolizing enzymes assayed from archived FFPE breast carcinoma and normal lymph node tissues.

\section{Materials and methods Study population}

This study was approved by the Boston University Medical Campus Institutional Review Board and the Regional Committee on Biomedical Research Ethics of Aarhus County, Denmark. We conducted the study among women aged 35-70 years who were diagnosed with incident invasive breast carcinoma, ie, Union for International Cancer Control (UICC) Stage I, II, or III, while living in one of seven counties in western Denmark between 1985 and 2001. The study sample was identified using the Danish Breast Cancer Cooperative Group registry to study associations between polymorphisms in genes encoding drug-metabolizing enzymes and tamoxifen resistance. Cases were defined as women with local or distant breast cancer recurrence. One recurrence-free control was incidence-density sampled and matched to each case for estrogen receptor expression, receipt of tamoxifen therapy, menopausal status at diagnosis (pre- or postmenopausal), date of breast cancer surgery (calipermatched \pm 12 months), county of residence at diagnosis, and UICC stage at diagnosis (Stage I, II, or III). For each case and control, FFPE primary breast tumors were requested from the pathology departments at the admitting hospitals.
Cancer-free FFPE lymph node tissue resected during primary surgical treatment was also requested for cases and controls when such tissue was available. For the present study, we aimed to enroll approximately 100 subjects for whom both tumor and normal tissues were received from pathology departments.

\section{Tissue processing}

Hematoxylin and eosin stained sections or written pathologic descriptions of the tumor and lymph node tissue blocks were reviewed by a pathologist to identify blocks for processing. Tissue blocks were processed in a laminar flow hood that had been sterilized with at least one hour of ultraviolet light exposure before use. Contaminating nucleases were removed by wiping all work surfaces and instruments with an aqueous solution of $1 \%(\mathrm{w} / \mathrm{v})$ sodium dodecyl sulfate, followed by 99.9\% ethanol. Several sections were cut from each tissue block and discarded to ensure a clean starting surface for sample procurement. For DNA extractions, three to six $10 \mu \mathrm{m}$ pieces were cut from each lymph node and tumor tissue block and placed in a $1.5 \mathrm{~mL}$ microtube. The cutting knife was wiped clean with the sodium dodecyl sulfate/ethanol series after each block, and the blade was replaced after every two blocks. Each blade was long enough to permit the cutting of two blocks without cross-contamination. Laboratory personnel changed gloves between blocks, and cut a pure paraffin control block after every 10 tissue blocks to serve as a contamination checkpoint.

\section{DNA extraction}

Before DNA extraction, all tissue samples were deparaffinized by treatment with xylene; $1 \mathrm{~mL}$ of xylene was added to each microtube containing three to six slices of paraffinembedded tissue and the microtubes were placed in a shaking incubator at $45^{\circ} \mathrm{C}$ and $800 \mathrm{rpm}$ for 20 minutes. Samples were then centrifuged at 12,200 rpm for five minutes, after which the supernatant was removed and discarded. The xylene treatment steps were repeated once for all samples. After deparaffinization, samples were incubated with $1 \mathrm{~mL}$ of $99 \%$ ethanol in a shaking incubator at $60^{\circ} \mathrm{C}$ and $800 \mathrm{rpm}$ for 20 minutes, centrifuged at 12,200 rpm for five minutes, with subsequent removal of supernatant; ethanol treatment was repeated once for all samples. One drop of acetone was added to each tube, and tissue samples were evaporated to dryness at $60^{\circ} \mathrm{C}$. Tissues were then allowed to dissolve overnight in a shaking incubator at $55^{\circ} \mathrm{C}$ and $1000 \mathrm{rpm}$ after addition of $150 \mu \mathrm{L}$ proteinase $\mathrm{K}(10 \mathrm{mg} / \mathrm{mL})$ solution. The following morning, proteinase $\mathrm{K}$ was inactivated by a 20 -minute 
incubation at $98^{\circ} \mathrm{C}$. DNA was then extracted from the tissue samples using a robotic magnet-assisted nucleic acid isolation instrument (MagnaPure, Roche Applied Science).

\section{Genotyping}

From each tissue sample, $50 \mathrm{ng}$ of extracted DNA were amplified in $25 \mu \mathrm{L}$ polymerase chain reactions with 50 denaturation cycles at $92^{\circ} \mathrm{C}$ for 15 seconds, followed by annealing and extension at $60^{\circ} \mathrm{C}$ for 90 seconds, using primers and reagents supplied with TaqMan genotyping kits (Applied BioSystems, Foster City, CA). We compared normal lymph node tissue with tumor tissue on genotypes of three metabolic enzyme single-nucleotide polymorphisms (SNPs), ie, cytochrome P450 2D6 (CYP2D6)*4 (rs3892097, ABI kit: C-27102431-D0); UDP-glucuronosyltransferase 2B15 $(U G T 2 B 15) * 2$ (rs1902023, ABI kit: C-27028164-10); and UDP-glucuronosyltransferase 1A8 (UGT1A8)*2 (rs1042597, ABI kit: C-11742072-10). Additional data on these SNPs are shown in Table 1 . These genes were selected for analysis because each plays a key role in the phase I (CYP2D6) or phase II ( $U G T 2 B 15$ and $U G T 1 A 8)$ metabolism of tamoxifen, and it is hypothesized that functional polymorphisms at these loci may modify the effectiveness of adjuvant tamoxifen therapy. ${ }^{5,13-17}$ All sample pairs were assayed in duplicate using the MX3000P real-time polymerase chain reaction system (Stratagene, Cedar Creek, TX). Positive controls for each variant were identified by sequencing peripheral blood DNA from 30 healthy individuals and included with each set of assays. Negative controls, with sterile water substituted for DNA, were also included in each run. Genotypes were classified as homozygous wild-type, homozygous variant, or heterozygous according to the autocall feature of the analytic software (MXPro QPCR version 4.1, Stratagene). If a sample failed to yield a called genotype it was reassayed using $70 \mathrm{ng}$ of DNA in the amplification reaction. If the sample failed again, a new tissue section was cut from the paraffin block and the yield from the new DNA extraction was used for reassay. Samples that failed after re-extraction were excluded from the study.

\section{Statistical analysis}

For all genes, we crosstabulated genotype frequencies according to tissue type (normal lymph node and tumor) and calculated weighted kappa coefficients as a measure of agreement between the two DNA sources. ${ }^{18}$ Because our kappa statistics were calculated from samples of modest size and were either approximately or exactly equal to unity, we calculated $95 \%$ confidence intervals (CI) around the point estimates by characterizing the 2.5 th and 97.5 th percentiles of distributions of estimated kappas from 1000 bootstrapped samples of the original data. ${ }^{19}$ We also calculated percent agreement and corresponding mid- $P$ 95\% CI under a binomial distribution. ${ }^{20}$ We calculated observed allele frequencies for each gene variant, based upon results from normal lymph node tissue, and compared these with benchmark values previously reported in European or Caucasian populations. We used observed and expected allele frequencies from normal lymph node tissue to calculate Chi-square statistics and test the null hypothesis that allele frequencies were in Hardy-Weinberg equilibrium. All statistical tests were two-sided, with a Type I error rate of 5\%. All analyses were performed using SAS version 9.1 (SAS Institute, Cary, NC).

\section{Results}

There were 106 paired normal lymph node and breast tumor tissue samples from the individual patients included in this study. The distribution of the paired samples according to key clinical characteristics is reported in Table 2.

Table I Summary data for the SNPs analyzed for tumor/normal tissue genotype concordance

\begin{tabular}{|c|c|c|c|c|}
\hline Gene/variant & Reference SNP & Location & Sequence [SNP] & $\begin{array}{l}\text { Expected allele } \\
\text { frequencies }\end{array}$ \\
\hline Cytochrome P450 2D6/ CYP2D6*4 & rs3892097 & $22 q \mid 3.1$ & $\begin{array}{l}\text { CCCCTTACCCGCATCTCCCACCCCCA } \\
{[A / G]} \\
\text { GACGCCCCTTTCGCCCCAACGGTCT }\end{array}$ & $\begin{array}{l}\text { A: } 0.763 \\
G: 0.237^{a}\end{array}$ \\
\hline $\begin{array}{l}\text { UDP-glucuronosyltransferase } 2 \mathrm{~B} \mid 5 / \\
\text { UGT2B } 15 * 2\end{array}$ & rs 1902023 & $4 q 13$ & $\begin{array}{l}\text { TTTATCCTACATCTTTAACTAAAAAT } \\
{[\text { G/T] }} \\
\text { ATTTGGAAGATTCTCTTCTGAAAAT }\end{array}$ & $\begin{array}{l}\mathrm{G}: 0.560 \\
\mathrm{~T}: 0.440^{\mathrm{b}}\end{array}$ \\
\hline $\begin{array}{l}\text { UDP-glucuronosyltransferase IA8/ } \\
\text { UGTIA8*2 }\end{array}$ & rs 1042597 & $2 q 37$ & $\begin{array}{l}\text { CTCTGTGGTCTTCGCCAGGGGAATAG } \\
\text { [C/G] } \\
\text { TTGCCACTATCTTGAAGAAGGTGCA }\end{array}$ & $\begin{array}{l}\text { C: } 0.714 \\
\text { G: } 0.286^{\mathrm{a}}\end{array}$ \\
\hline
\end{tabular}

Notes: aAllele frequencies reported for Caucasians on NCBI dbSNP database: http://www.ncbi.nlm.nih.gov/snp; bAllele frequencies reported for Europeans on ALFRED database: http://alfred.med.yale.edu ${ }^{21}$

Abbreviation: SNP, single nucleotide polymorphism. 
Table 2 Distribution of 106 tumor and normal tissue pairs according to demographic and clinical factors

\begin{tabular}{|c|c|}
\hline Characteristic & $\begin{array}{l}\text { Paired tissue } \\
\text { samples, n (\%) }\end{array}$ \\
\hline \multicolumn{2}{|l|}{ Patient age at diagnosis (y) } \\
\hline $35-44$ & $8(7.6)$ \\
\hline $45-54$ & $25(24)$ \\
\hline $55-64$ & $42(40)$ \\
\hline $65-70$ & $31(29)$ \\
\hline \multicolumn{2}{|l|}{ Year of diagnosis } \\
\hline 1985-1993 & $33(3 \mathrm{I})$ \\
\hline $1994-1996$ & $36(34)$ \\
\hline$|997-200|$ & $37(35)$ \\
\hline \multicolumn{2}{|l|}{ UICC tumor stage at diagnosis } \\
\hline Stage I & $2(1.9)$ \\
\hline Stage II & $60(57)$ \\
\hline Stage III & $44(42)$ \\
\hline \multicolumn{2}{|l|}{ Type of primary surgery } \\
\hline Mastectomy & $93(88)$ \\
\hline Breast-conserving surgery & $12(11)$ \\
\hline Other & $\mathrm{I}(0.9)$ \\
\hline \multicolumn{2}{|c|}{ Systemic adjuvant chemotherapy ${ }^{a}$} \\
\hline Yes & $79(75)$ \\
\hline No & $27(26)$ \\
\hline \multicolumn{2}{|l|}{ Radiation therapy } \\
\hline Yes & $63(59)$ \\
\hline No & $36(34)$ \\
\hline Missing & $7(6.6)$ \\
\hline
\end{tabular}

Note: aDuring the study period chemotherapy was limited to the adjuvant setting only.

Abbreviation: UICC, Union for International Cancer Control.

We successfully assayed $C Y P 2 D 6^{*} 4$ genotype in 105 pairs $(99 \%), U G T 1 A 8^{*} 2$ genotype in 89 pairs $(84 \%)$, and $U G T 2 B 15^{*} 2$ genotype in 106 pairs $(100 \%)$. There was no difference between samples that genotyped successfully and those that failed to genotype successfully with regard to DNA purity ( $A_{260} / A_{280}$ measurement), DNA concentration, length of amplified sequence, or age of the tissue block at the time of DNA extraction. Our main analyses are based on sample pairs with successfully assayed genotypes from both tissue sources.

Table 3 reports the crosstabulation of genotype frequencies according to lymph node and tumor-derived DNA, the kappa statistic for agreement between the two tissue types, and results from Chi-square tests for Hardy-Weinberg equilibrium based on genotype frequencies from the normal tissue samples. For all three genes, allele frequencies observed in our study sample agreed with values reported in similar populations (Tables 1 and 3). Wild-type and variant allele frequencies for all three genes did not deviate from HardyWeinberg equilibrium ( $P \geq 0.11$ for all Chi-square tests). Genotyping concordance was perfect for the CYP2D6*4 and $U G T 1 A 8^{*} 2$ variants (for both, weighted kappa $=1.00$;
$95 \%$ CI $1.00,1.00)$. Among the 106 pairs with a successfully assayed $U G T 2 B 15 * 2$ genotype, one pair $(0.9 \%)$ gave a discordant result. The normal lymph tissue indicated a homozygous variant genotype and the tumor tissue indicated a homozygous wild-type genotype (weighted kappa $=0.97$; $95 \%$ CI $0.91,1.00)$. This outcome was consistent across four repeated assays on the discordant pair, even after re-extraction of DNA from the source tissue blocks.

\section{Discussion}

Our study demonstrated high concordance between breast tumor- and normal lymph node-derived genotypes for key SNPs in drug-metabolizing enzymes, and agrees with observations from similar earlier studies. Previous work by Rae et al showed $100 \%$ concordance between CYP2D6 genotypes from 10 FFPE archival breast tumors and matched peripheral blood samples. ${ }^{6}$ Schneider et al demonstrated $100 \%$ concordance between 17 breast tumor and lymph node samples for polymorphisms in two angiogenesis genes. ${ }^{11}$ Xie et al reported 100\% concordance for five genes from different high loss of heterozygosity sites in 106 paired samples of peripheral blood and microdissected normal tissue adjacent to breast tumor tissue. ${ }^{12}$ Our study provides evidence that breast tumor-derived genotypes are an acceptable proxy for germline genotypes when more suitable DNA sources are not available. This finding agrees with conclusions from two earlier reviews on this topic, ${ }^{21,22}$ and with results from other concordance studies using colorectal ${ }^{23}$ and non-small cell lung ${ }^{24}$ tumor DNA.

One of our target genes, CYP2D6, is located in a chromosomal region (22q13.1) that is commonly deleted in breast cancer cells. ${ }^{8}$ Thus, SNPs in CYP2D6 assayed from tumorderived DNA are at risk of misclassification due to loss of heterozygosity, yielding the expectation of imperfect genotype concordance between normal and tumor-derived DNA. The other SNPs lie in chromosomal regions that experience little or no deletion, so there is less expectation of imperfect concordance between normal and tumor-derived DNA for them. The perfect concordance we observed between CYP2D6 genotypes from the two different tissue types indicates either that loss of heterozygosity does not meaningfully distort CYP2D6 genotype classification in breast tumor cells, or that despite substantial loss of heterozygosity, tumor sections contain sufficient stromal or adjacent normal tissue to report an accurate germline genotype. The perfect concordance observed by Xie et al in five genes from high loss of heterozygosity sites also supports these notions, providing reassurance that loss of heterozygosity is not a major threat 
Table 3 Cross tabulation of genotypes determined using DNA extracted from formalin-fixed, paraffin-embedded tumor and normal tissue from Danish breast cancer patients

\begin{tabular}{|c|c|c|c|c|c|c|}
\hline \multirow{2}{*}{$\begin{array}{l}\text { Gene variant } \\
\text { (Hardy-Weinberg } \\
\text { P value) }\end{array}$} & \multirow[t]{2}{*}{ Tumor tissue genotypes } & \multicolumn{3}{|c|}{ Normal tissue genotypes } & \multicolumn{2}{|c|}{ Concordance } \\
\hline & & wt/wt & wt/var & var/var & $\begin{array}{l}\text { Weighted } \mathrm{K} \\
(95 \% \mathrm{CI})\end{array}$ & $\begin{array}{l}\text { Agreement \% } \\
(95 \% \mathrm{Cl})\end{array}$ \\
\hline \multirow{5}{*}{ CYP2D6*4 $(P=0.46)$} & wt/wt & 66 & 0 & 0 & 1.00 & 100 \\
\hline & wt/var & 0 & 36 & 0 & $(1.00,1.00)$ & $(97.2,100)$ \\
\hline & var/var & 0 & 0 & 3 & & \\
\hline & Normal tissue allele frequencies & G: 0.80 & & & & \\
\hline & & A: 0.20 & & & & \\
\hline \multirow[t]{5}{*}{ UGT2BI5*2 $(P=0.1 \mathrm{I})$} & $w t / w t$ & 25 & 0 & 1 & 0.97 & 98.9 \\
\hline & wt/var & 0 & 61 & 0 & $(0.91,1.00)$ & $(95.4,99.1)$ \\
\hline & var/var & 0 & 0 & 19 & & \\
\hline & Normal tissue allele frequencies & G: 0.52 & & & & \\
\hline & & $\mathrm{T}: 0.48$ & & & & \\
\hline \multirow[t]{5}{*}{ UGTIA8*2 $(P=0.22)$} & $w t / w t$ & 47 & 0 & 0 & 1.00 & 100 \\
\hline & wt/var & 0 & 32 & 0 & $(1.00,1.00)$ & $(96.7,100)$ \\
\hline & var/var & 0 & 0 & 10 & & \\
\hline & Normal tissue allele frequencies & G: $0.7 \mathrm{I}$ & & & & \\
\hline & & $A: 0.29$ & & & & \\
\hline
\end{tabular}

Abbreviations: wt, wild-type; var, variant; $\mathrm{Cl}$, confidence interval.

to genotype misclassification when breast tumor-derived DNA must be relied upon.

A limitation of our study is that our standard for germline genotype was DNA extracted from FFPE normal lymphatic tissue instead of from fresh nonmalignant tissue. Earlier work by Rae et al showed 100\% genotype concordance between DNA from freshly harvested tumor cell cultures and DNA from tumor cell pellets that were formalin-fixed and embedded in paraffin before DNA extraction. ${ }^{6}$ Therefore, we consider our FFPE normal lymphatic tissue to be an accurate standard for the germline genotype that would be observed using fresh tissue.

In summary, we observed excellent agreement between archived breast tumor- and normal lymphatic tissue-derived DNA in classifying the germline genotype of three drugmetabolizing enzyme variants $\left(C Y P 2 D 6^{*} 4, U G T 1 A 8^{*} 2\right.$, and $\left.U G T 2 B 15^{*} 2\right)$ in sample sizes ranging from 89 to 106. Only one of the assayed gene variants $(U G T 2 B 15 * 2)$ gave a discrepant result, although in only one of 106 tested pairs. The discrepant result was a shift from homozygous wild-type in normal lymphatic tissue to a homozygous variant in the breast tumor tissue, in a chromosomal region not typically deleted in breast cancer. ${ }^{8}$ Therefore, while it is possible that the discrepancy arose from a tumor genome alteration, it is more plausible that a clerical error during either tissue archiving or processing resulted in the pairing of tumor and lymphatic tissues from separate patients.

Together, our observations indicate that FFPE archived breast tumors provide a reliable resource for the determination of germline genotypes in CYP2D6, UGT2B15, UGT1A8, and likely other drug-metabolizing enzymes. It remains possible that mutations at other loci on the tumor genome could yield poorer concordance proportions than those observed for the three metabolic enzyme variants we studied. Our finding is important because genotyping DNA extracted from tumor tissue avoids the time-consuming practice of microdissection of adjacent normal tissue when other sources of normal tissue (eg, peripheral blood or lymph node) are not available. Study resources can then be devoted more cost-efficiently to, for example, increase sample size or genotyping capacity.

\section{Acknowledgments}

The authors are most grateful to Kristina L Lauridsen, Jesper Bertelsen, and Inge K Krohn for their outstanding technical assistance. This research was supported by grants from the US National Cancer Institute (R01 CA118708), the Danish Cancer Society (DP06117), and the Karen Elise Jensen Foundation. Mr Ahern's effort on this study was supported by a CDMRP predoctoral training award (BC073012).

\section{Disclosure}

The Department of Clinical Epidemiology at Aarhus University Hospital is involved in studies with funding from various companies as research grants to, and administered by, Aarhus University. None of these studies is related to the present study or supported any of the work reported herein. No author has any other potential competing interest. 


\section{References}

1. Braakhuis BJ, Tabor MP, Kummer JA, Leemans CR, Brakenhoff RH. A genetic explanation of Slaughter's concept of field cancerization: Evidence and clinical implications. Cancer Res. 2003;63(8): 1727-1730.

2. Deng G, Lu Y, Zlotnikov G, Thor AD, Smith HS. Loss of heterozygosity in normal tissue adjacent to breast carcinomas. Science. 1996;274(5295): 205-209.

3. Larson PS, de las Morenas A, Bennett SR, Cupples LA, Rosenberg CL. Loss of heterozygosity or allele imbalance in histologically normal breast epithelium is distinct from loss of heterozygosity or allele imbalance in co-existing carcinomas. Am J Pathol. 2002;161(1):283-290.

4. Shibata D, Martin WJ, Arnheim N. Analysis of DNA sequences in forty-year-old paraffin-embedded thin-tissue sections: A bridge between molecular biology and classical histology. Cancer Res. 1988;48(16): 4564-4566.

5. Higgins MJ, Stearns V. CYP2D6 polymorphisms and tamoxifen metabolism: Clinical relevance. Curr Oncol Rep. 2010;12(1):7-15.

6. Rae JM, Cordero KE, Scheys JO, Lippman ME, Flockhart DA, Johnson MD. Genotyping for polymorphic drug metabolizing enzymes from paraffin-embedded and immunohistochemically stained tumor samples. Pharmacogenetics. 2003;13(8):501-507.

7. Weiss JR, Baer MR, Ambrosone CB, et al. Concordance of pharmacogenetic polymorphisms in tumor and germ line DNA in adult patients with acute myeloid leukemia. Cancer Epidemiol Biomarkers Prev. 2007;16(5):1038-4101.

8. Osborne RJ, Hamshere MG. A genome-wide map showing common regions of loss of heterozygosity/allelic imbalance in breast cancer. Cancer Res. 2000;60(14):3706-3712.

9. Miller BJ, Wang D, Krahe R, Wright FA. Pooled analysis of loss of heterozygosity in breast cancer: A genome scan provides comparative evidence for multiple tumor suppressors and identifies novel candidate regions. Am J Hum Genet. 2003;73(4):748-767.

10. Stephens PJ, McBride DJ, Lin ML, et al. Complex landscapes of somatic rearrangement in human breast cancer genomes. Nature. 2009; 462(7276):1005-1010.

11. Schneider BP, Skaar TC, Sledge GW, Badve S, Li L, Flockhart DA. Analysis of angiogenesis genes from paraffin-embedded breast tumor and lymph nodes. Breast Cancer Res Treat. 2006;96(3):209-215.

12. Xie B, Freudenheim JL, Cummings SS, et al. Accurate genotyping from paraffin-embedded normal tissue adjacent to breast cancer. Carcinogenesis. 2006;27(2):307-310.
13. Wegman P, Elingarami S, Carstensen J, Stal O, Nordenskjold B, Wingren S. Genetic variants of CYP3A5, CYP2D6, SULT1A1, UGT2B15 and tamoxifen response in postmenopausal patients with breast cancer. Breast Cancer Res. 2007;9(1):R7.

14. Nowell SA, Ahn J, Rae JM, et al. Association of genetic variation in tamoxifen-metabolizing enzymes with overall survival and recurrence of disease in breast cancer patients. Breast Cancer Res Treat. 2005; 91(3):249-258.

15. Borges S, Desta Z, Li L, et al. Quantitative effect of CYP2D6 genotype and inhibitors on tamoxifen metabolism: implication for optimization of breast cancer treatment. Clin Pharmacol Ther. 2006;80(1):61-74.

16. Sun D, Sharma AK, Dellinger RW, et al. Glucuronidation of active tamoxifen metabolites by the human UDP glucuronosyltransferases. Drug Metab Dispos. 2007;35(11):2006-2014.

17. Zheng Y, Sun D, Sharma AK, Chen G, Amin S, Lazarus P. Elimination of antiestrogenic effects of active tamoxifen metabolites by glucuronidation. Drug Metab Dispos. 2007;35(10):1942-1948.

18. Stokes ME, Davis CS, Koch GG. Categorical Data Analysis using the SAS System. 2nd ed. Cary, NC: SAS Institute; 2000.

19. Vierkant RA. A SAS macro for calculating bootstrapped confidence intervals about a kappa coefficient. Proceedings of the Twenty-Second Annual SAS Users Group International Conference. Cary, NC: SAS Institute Inc; 1997.

20. Greenland S, Lash TL, Rothman KJ. Fundamentals of epidemiologic data analysis. In: Rothman KJ, Greenland S, Lash TL, editors. Modern Epidemiology. 3rd ed. Philadelphia, PA: Lippincott Williams and Wilkins; 2008.

21. Innocenti F, Marsh S. Concordance between tumor and germline DNA. Genomics and Pharmacogenomics in Anticancer Drug Development and Clinical Response: Totowa, NJ: Humana Press; 2009.

22. McWhinney SR, McLeod HL. Using germline genotype in cancer pharmacogenetic studies. Pharmacogenomics. 2009;10(3):489-493.

23. Marsh S, Mallon MA, Goodfellow P, McLeod HL. Concordance of pharmacogenetic markers in germline and colorectal tumor DNA. Pharmacogenomics. 2005;6(8):873-877.

24. Liu G, Cheng D, le Maitre A, et al. Genetic polymorphisms as prognostic/predictive biomarkers of single-agent erlotinib therapy in NCICCTG BR.21 Non-small cell lung cancer (NSCLC) trial. Brighton, UK: International Congress of Pharmacoepidemiology; 2010.
Clinical Epidemiology

\section{Publish your work in this journal}

Clinical Epidemiology is an international, peer-reviewed, open access journal focusing on disease and drug epidemiology, identification of risk factors and screening procedures to develop optimal preventative initiatives and programs. Specific topics include: diagnosis, prognosis, treatment, screening, prevention, risk factor modification, systematic

Submit your manuscript here: http://www.dovepress.com/clinical-epidemiology-journal

\section{Dovepress}

reviews, risk \& safety of medical interventions, epidemiology \& biostatical methods, evaluation of guidelines, translational medicine, health policies \& economic evaluations. The manuscript management system is completely online and includes a very quick and fair peer-review system, which is all easy to use. 